\title{
Computer Vision Techniques in Forest Inventory Assessment: Improving Accuracy of Tree Diameter Measurement Using Smartphone Camera and Photogrammetry
}

\author{
Heesung Woo, ${ }^{1}$ Ikhyun Kim, ${ }^{2}$ and Byoungkoo Choi ${ }^{3 *}$ \\ ${ }^{1}$ College of Forest and Environmental Sciences, Kangwon National University, Chuncheon 24341, Korea \\ ${ }^{2}$ Department of Forestry and Environmental Systems, Kangwon National University, Chuncheon 24341, Korea \\ ${ }^{3}$ Division of Forest Sciences, Kangwon National University, Chuncheon 24341, Korea
}

(Received August 28, 2021; accepted October 5, 2021)

Keywords: computer vision, photogrammetry, tree diameter, forest inventory, image processing

The forest industry is facing many challenges, including lack of labor and low operational efficiency. In South Korea, the small-scale forest industry has hindered the development of advanced-level forest industry due to high cost of machines and sensors. To overcome these challenges, the application of ICT technologies can be considered a means of rehabilitating the Korean forest industry. As one approach, we investigated the possibility of using smartphoneintegrated computer vision in forest inventory assessment. Individual tree diameters were estimated using four different circular fitting algorithms: least-squares circle (C), minimum enclosing circle (MEC), convex hull (CH), and least-squares ellipse (E). We found that $\mathrm{C}$ and MEC were the most accurate algorithms for estimating the tree diameter in Pinus densiflora (PD) and Pinus koraiensis (PK) forest stands. The results of this research indicate the possibility of using smartphones to investigate the forest structure efficiently.

\section{Introduction}

Investigating the forest structure and inventory is critical in understanding forest ecosystems and value estimation. ${ }^{(1,2)}$ Traditionally, in forest inventory fieldwork, the diameter at breast height $(\mathrm{DBH})$ and tree height have been measured by foresters using mechanical or optical measurement tools, such as calipers, diameter tapes, and laser hypsometers in field plots. ${ }^{(3)}$ Tree height and DBH are the most common factors used to estimate stem volume. ${ }^{(3,4)}$ Accurate data of individual trees can support forest managers in value-optimized forest management planning with precise economic forecasting and decision making. ${ }^{(5)}$ However, these conventional methods have several drawbacks, such as high labor and time requirements. ${ }^{(6,7)}$ Additionally, most collected forest inventory data have measurement errors generated by personal bias or faulty instruments during the forest inventory fieldwork.

The quality of forest inventory data is directly related to the economic assessment of the forest industry. Thus, accurate tree height and DBH data are required to improve stem volume estimation. ${ }^{(8,9)}$ With the increased awareness of carbon sequestration and forest biomass energy

*Corresponding author: e-mail: bkchoi@kangwon.ac.kr https://doi.org/10.18494/SAM.2021.3605 
resources, accurate forest inventory measurement is essential to ensure the optimal use of forest and woody-biomass products. ${ }^{(2,5,10-14)}$ To overcome the above drawbacks, several studies investigated the use of innovative sensing technologies such as light detection and ranging (LIDAR) scanning of both terrestrial and airborne systems, which has great potential for improving the accuracy of forest structure data through the use of 3D point cloud data (PCD).

There is growing interest in using terrestrial laser scanning (TLS) and airborne laser scanning (ALS) systems to assess tree and forest biometric information based on 3D PCD. ${ }^{(15-18)}$ The 3D PCD generated from LIDAR sensors can not only provide DBH, tree height, and the volume of individual trees but is also valuable information for improving forest management and planning, ${ }^{(19-24)}$ including optimal forest inventory and biomass estimation. ${ }^{(25,26)}$

However, the application of LIDAR systems in TLS and ALS is limited by the high cost of LIDAR systems and analysis tools. Photogrammetric techniques have been introduced as an alternative to LIDAR-based approaches. Photogrammetry is the science of generating and exporting 3D point clouds from photographic images. ${ }^{(27)}$ The primary function of photogrammetry is to take multiple overlapping photographs of objects and convert them into 3D digital models. ${ }^{(5,10,26,28-32)}$ Several studies have investigated the feasibility of using photogrammetry as a source of PCD for measuring stem profiles as a cost-effective alternative to TLS. Miller et al. investigated the possibility of applying a handheld camera along with the structure-from-motion technique with multi-view stereo photogrammetry (SfM-MVS) to measure trees accurately. ${ }^{(29)}$ They found that SfM-MVS could produce 3D points with accuracy comparable to that of a LIDAR sensor.

Furthermore, Marzulli et al. ${ }^{(5)}$ estimated tree DBH and volume using a smartphone camera. They found that the image scale is the most important factor in identifying and extracting tree stems from the converted 3D PCD. They also demonstrated the potential of using a smartphone in photogrammetric and modeling methods to measure $\mathrm{DBH}$ and volume.

However, to date, there have been few technical and practical approaches for using smartphone photogrammetric PCD methods in tree stem and volume estimation in Korea. ${ }^{(33,34)}$ Moreover, there has been no relevant research on applying photogrammetry to major Korean tree species such as Pinus densiflora (PD) and Pinus koraiensis (PK). With this background, we investigated the possibility of estimating the tree diameter for PD and PK using smartphonebased photogrammetric PCD. We compared the accuracy of tree DBHs estimated using four different circular fitting algorithms, namely, minimum enclosing circle (MEC), convex hull $(\mathrm{CH})$, least-squares circle $(\mathrm{C})$, and least-squares ellipse $(\mathrm{E})$, with ground truth values (fieldmeasured $\mathrm{DBH}$ ). The results of this study will provide valuable information on future opportunities for the application of photogrammetry by forest researchers and managers interested in cost-efficient forest inventory assessment.

\section{Materials and Methods}

A flowchart of the overall research is presented in Fig. 1. The image data were acquired at research sites, and the collected images were processed and converted to 3D PCD format. The extracted $\mathrm{PCD}$ were simulated using the $\mathrm{C}, \mathrm{MEB}, \mathrm{CH}$, and $\mathrm{E}$ circular fitting algorithms to 


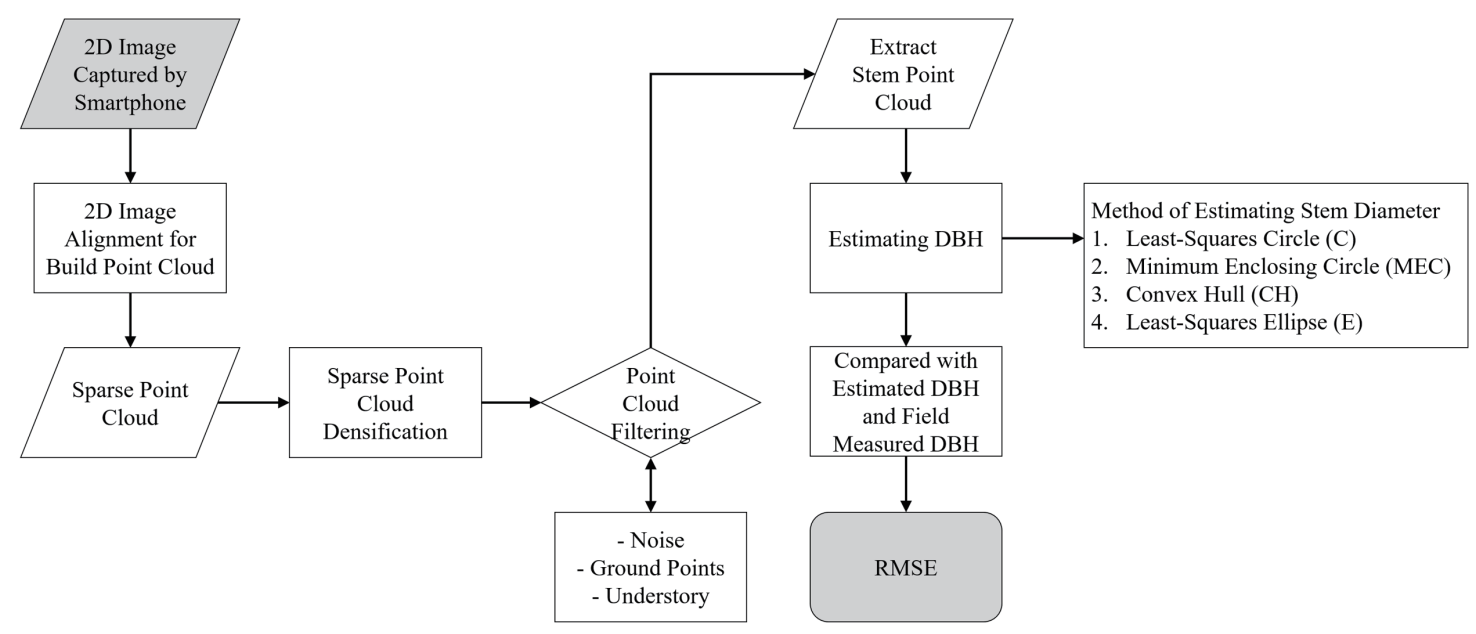

Fig. 1. Overall approach of tree diameter measurement using smartphone images based on photogrammetric methods.

estimate tree DBH. The results of DBH estimation were validated by comparison with fieldmeasured ground truth data. Detailed descriptions of the overall research process are presented below.

\subsection{Site description}

The study was conducted within the research forest of Kangwon National University, located in Bong-myeong, Hongcheon-gun, South Korea (Fig. 2). The total area of the research forest is 3139 ha and the area is covered with a range of mixed forests. The species distribution of the research forest is dominated by Korean white pine (PK), Japanese larch (Larix kaempferi), and Korean red pine (PD). The study sites were characterized by an even-aged plantation forest, and the target species were PD and PK. The fixed-radius plot method was adopted to collect field measurement sample data. In each sampling plot, a $10 \mathrm{~m}$ radius was measured from the center of the plot to surrounding trees using a DBH tape. Ten trees were randomly selected within the sampling plot to capture image data to enable photogrammetry surveys.

\subsection{Field survey and image acquisition for generating 3D PCD}

Tree DBH (measured at $1.2 \mathrm{~m}$ above ground level) was measured in the research site to validate the adopted $3 \mathrm{D}$ reconstruction fitting algorithms. $\mathrm{DBH}$ of individual trees was measured using a caliper (Haglöf Mantax Blue Caliper, Haglöf, Sweden) at $18^{\circ}$ intervals along concentric circular paths around the tree trunk. The mean value of DBH for a tree was calculated as a representative value to validate the estimation using the circular fitting algorithms. Individual tree images were captured with a mobile smartphone to generate 3D PCD using 2D images. In this study, a Samsung Galaxy S20 (Seoul, Korea), equipped with autofocusing and a 64-megapixel lens, was used to capture images. The 2D images were acquired from 23 to 28 


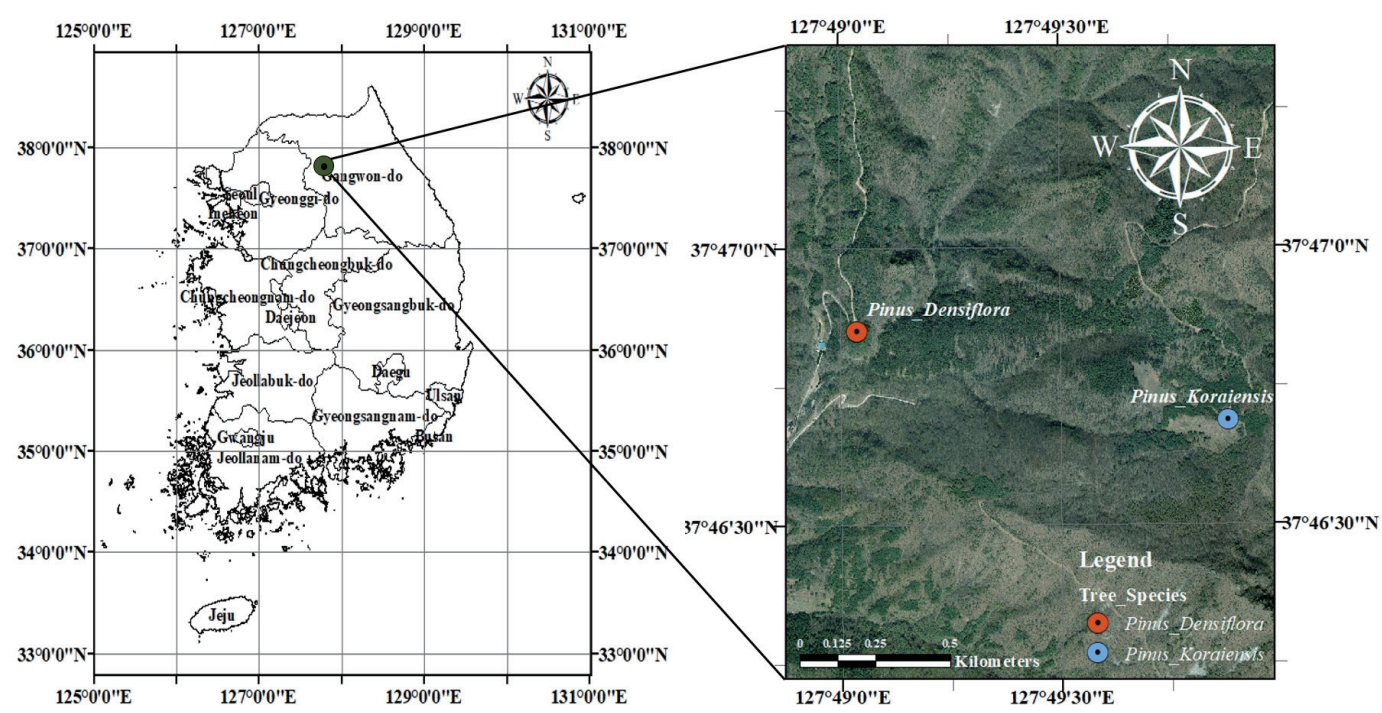

Fig. 2. (Color online) Location of research plot in research forest of Kangwon National University.

June 2021. The image-capturing procedure was adopted from that of Miller et al. ${ }^{(29)}$ Each tree was captured as 20 scenes from points at $18^{\circ}$ intervals along concentric circular paths around the tree trunk. Images were captured in such a way as to ensure a minimum of $50 \%$ coverage between any sequential pair; the image-capturing procedure involved moving $18^{\circ}$ sideways between each photo point in the inner circle, resulting in 20 images for each tree. The camera was marked with red flag tapes to indicate the locations of pictures taken along the circular path.

Additionally, the distance between the photo point and object tree was set to $2 \mathrm{~m}$ so that the tree trunk could fit within a single camera lens frame. Also, to maintain the vertical location of the camera lens, the camera elevation at each photo point was calibrated using a measuring staff. Lastly, 16-bit digit markers were printed and installed on the edge of the tree trunk to optimize the photo alignment progress (Fig. 3).

\subsection{Data processing and 3D model reconstruction with structure from motion ( $\mathrm{SfM}$ )}

As before, tree DBH (measured at $1.2 \mathrm{~m}$ above ground level) was measured in the research site to validate the adopted $3 \mathrm{D}$ reconstruction fitting algorithms. Individual tree $\mathrm{DBH}$ was measured using a caliper (Haglöf Mantax Blue Caliper) at $18^{\circ}$ intervals along concentric circular paths around the tree trunk. The mean value of DBH for a tree was calculated as a representative value to validate the estimated circular fitting results. The $2 \mathrm{D}$ images were aligned using Agisoft Metashape Professional (Version 1.5.1 build 7618) and a dense point cloud was generated. This tool provides a fully automated photogrammetric function for multiple images. Detailed descriptions of the analysis process were presented in Miller et al. ${ }^{(29)}$ The extracted 3D PCD were processed using an Intel Xeon CPU 64-bit system (3.4 GHz, 12 GB RTX 3080 Nvidia GPU, and 128.0 GB RAM), and the process took around $20 \mathrm{~min}$ for each tree measurement. 


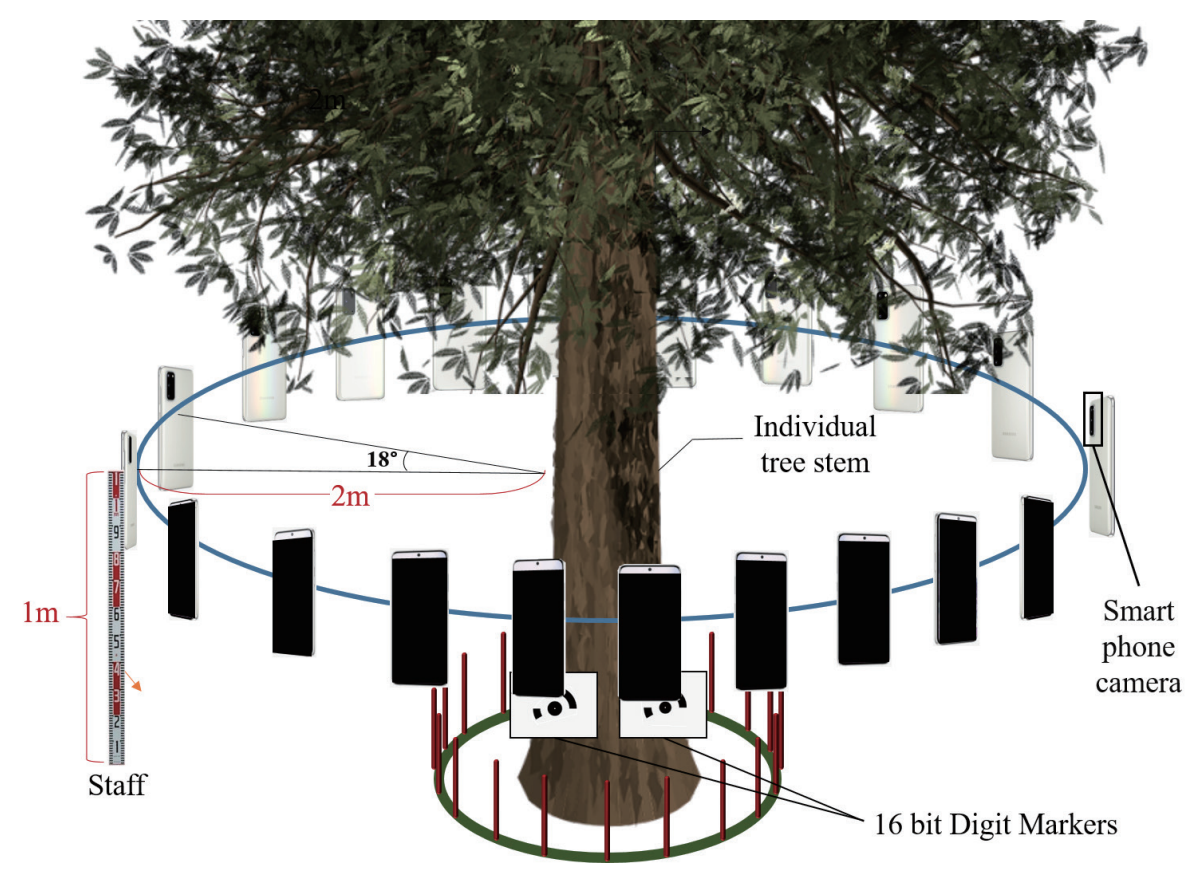

Fig. 3. (Color online) Overall image acquisition process using smartphone camera (Samsung Galaxy S20).

\subsection{Tree diameter assessment using circular fitting algorithms}

The accuracy of the estimated diameters of individual trees was compared with the ground truth data (field-measured diameters) at the same location. The PCD of individual trees were manually segmented. The location of the diameter was automatically extracted on the basis of breast height $(1.2 \mathrm{~m})$ from the ground level. Individual tree diameters were used to determine DBH using four different circular fitting algorithms: (1) C, (2) MEC, (3) CH, and (4) E (Fig. 4). These four circular fitting algorithms are described in detail in Ref. 35. The estimated DBHs were analyzed in MATLAB R2019B (9.7.0.1190202). Additionally, the estimated tree diameter accuracy was validated using root mean square error (RMSE) and bias, respectively defined as

$$
\begin{gathered}
\text { RMSE }=\sqrt{\frac{\sum\left(\hat{x}_{i}-x_{i}\right)^{2}}{n},} \\
\text { Bias }=\frac{1}{n} \sum_{i=1}^{n}\left(\hat{x}_{i}-x_{i}\right),
\end{gathered}
$$

where $n$ is the number of estimates, $\hat{x}_{i}$ is the estimated diameter, and $x_{i}$ is the field-measured ground truth data. Data analysis was performed using R v. 3.6.0 (R Core Team, 2021). To compare the estimated diameters of individual trees among the different circular fitting algorithms, one-way analysis of variance (ANOVA) was used. 


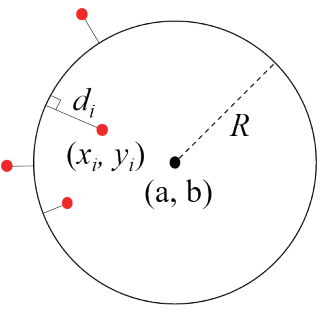

Least-Squares Circle

(C)

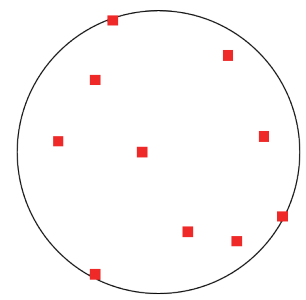

Minimum Enclosing Circle (MEC)

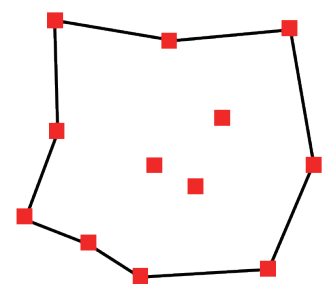

Convex Hull $(\mathrm{CH})$

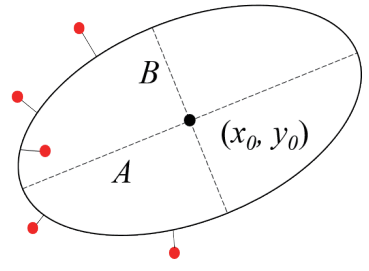

Least-Squares Ellipse

(E)

Fig. 4. (Color online) Circular fitting algorithms used to estimate tree diameter.

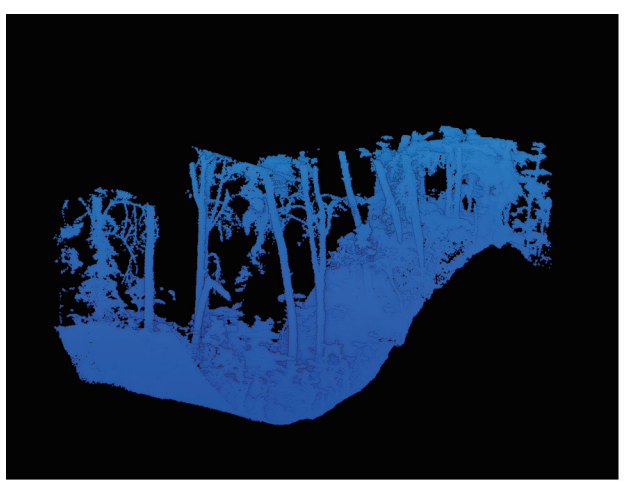

(a)

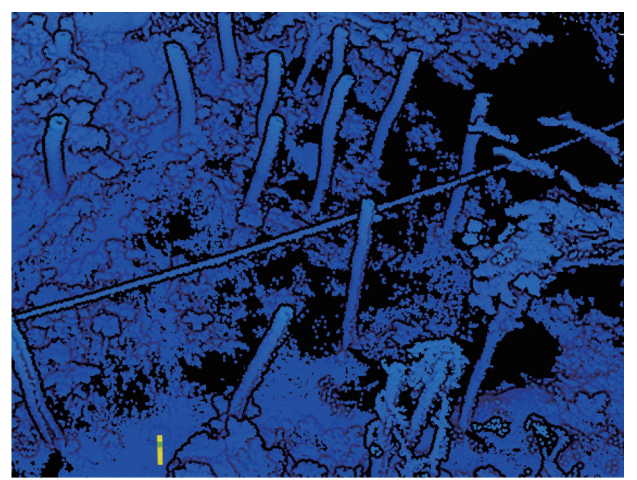

(b)

Fig. 5. (Color online) Reconstructed PCD of research plots: (a) PD stand, (b) PK stand.

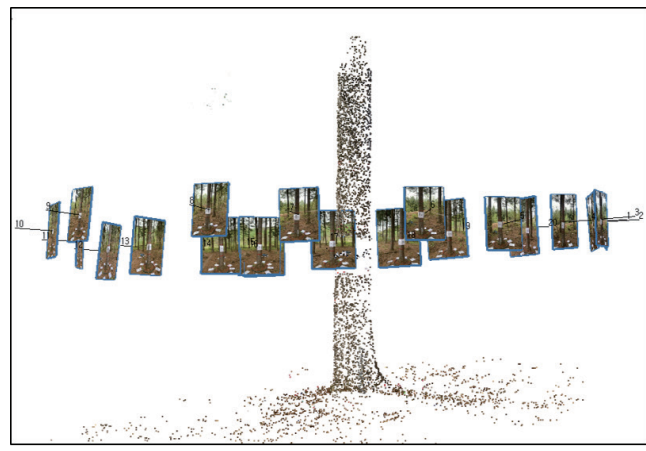

(a)

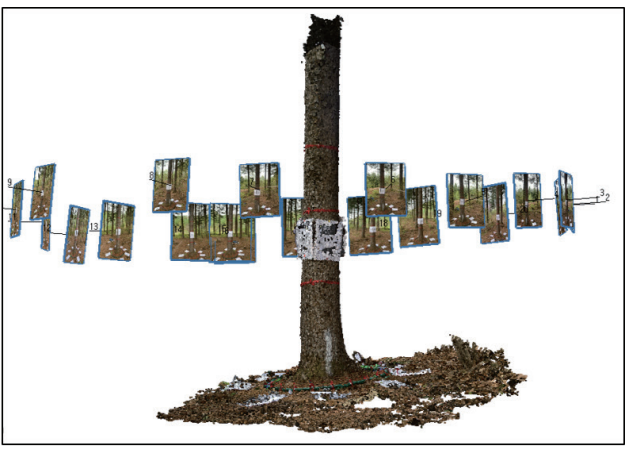

(b)

Fig. 6. (Color online) Reconstructed PCD of individual trees: (a) result of photo alignment and (b) visualization of reconstructed individual tree stem.

\section{Results}

\subsection{Generating PCD from captured images}

PCD of individual trees were successfully reconstructed. Figure 5 presents the converted PCD of research sites in PD and PK single-species stands. The alignment success rate based on 16-bit marker alignment was greater than $85 \%$. Individual tree images were reconstructed to estimate individual tree diameters as presented in Fig. 6. For the PCD reconstruction within the 
PD stand, the total numbers of reconstructed sparse and dense clouds were 75997 and 117626786 , respectively. Also, the numbers of reconstructed sparse and dense clouds in the PK plot were 60556 and 125502299 , respectively (Table 1).

\subsection{Individual tree diameter estimation for different circular fitting algorithms}

A total of ten trees were selected to estimate the diameter in both PD and PK plots. To estimate the diameter of individual trees, the PCD at DBH were extracted using the $z$ value. The extracted PCD are presented in Fig. 7. The estimated results of individual tree DBH in the PD and PK stands are presented in Tables 2 and 3, respectively. C exhibited the most accurate diameter estimation among the circular fitting algorithms when compared with the ground truth data (field-measured DBH) within the PD stand. The largest gap between the estimated results and the ground truth data was found for $\mathrm{E}$ in the PD and PK stands. According to the result of ANOVA, the DBH estimated by E was significantly different from those estimated by C, MEC,

Table 1

Numbers of reconstructed points and generated PCD for each tree species.

\begin{tabular}{|c|c|c|c|c|c|}
\hline \multirow{2}{*}{$\begin{array}{l}\text { Individual } \\
\text { tree }\end{array}$} & \multirow{2}{*}{$\begin{array}{l}\text { Number of } \\
\text { 2D images }\end{array}$} & \multicolumn{2}{|c|}{ PD } & \multicolumn{2}{|c|}{ PK } \\
\hline & & Tie points & Dense cloud points & Tie points & Dense cloud points \\
\hline 1 & & 10080 & 10133166 & 9321 & 13220910 \\
\hline 2 & & 6022 & 13160713 & 9201 & 14210463 \\
\hline 3 & & 4740 & 12254614 & 8880 & 13924830 \\
\hline 4 & & 8296 & 13818323 & 3149 & 13668546 \\
\hline 5 & & 7237 & 12050569 & 4277 & 13749734 \\
\hline 6 & 20 & 7663 & 9939743 & 4172 & 8661971 \\
\hline 7 & & 12144 & 15471579 & 4703 & 10549215 \\
\hline 8 & & 5467 & 11282308 & 6456 & 12511559 \\
\hline 9 & & 10097 & 10162894 & 4037 & 9654587 \\
\hline 10 & & 4250 & 9352877 & 6360 & 15350484 \\
\hline Total & 200 & 75997 & 117626786 & 60556 & 125502299 \\
\hline
\end{tabular}

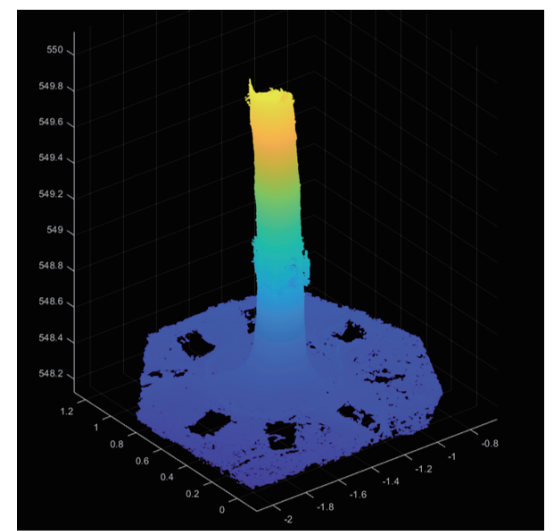

(a)

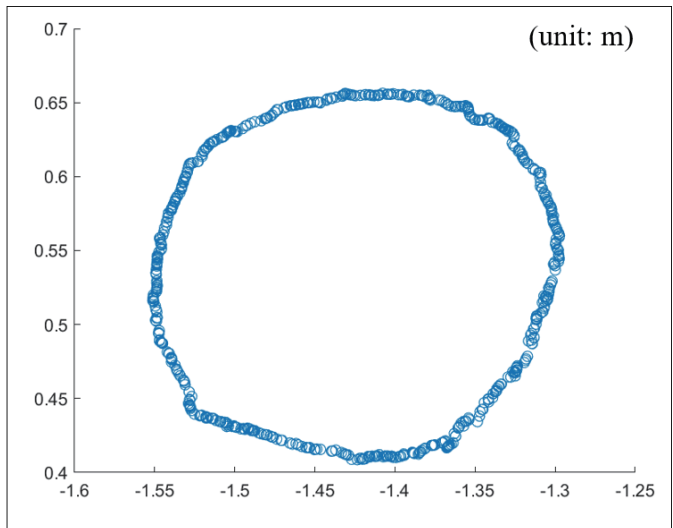

(b)

Fig. 7. (Color online) Reconstructed PCD of an individual tree: (a) PCD of whole tree, (b) PCD extracted at DBH (at $1.2 \mathrm{~m}$ above ground level) to estimate the DBH. 
Table 2

Tree DBH estimated using circular fitting algorithms in PD stand.

\begin{tabular}{|c|c|c|c|c|c|c|}
\hline \multirow{2}{*}{$\begin{array}{l}\text { Individual } \\
\text { tree }\end{array}$} & \multirow{2}{*}{ Tolerance $^{\mathrm{a}}$} & \multicolumn{5}{|c|}{ Estimated tree DBH (error between estimated DBH and ground truth) } \\
\hline & & $\mathrm{C}$ & MEC & $\mathrm{CH}$ & $\mathrm{E}$ & Ground truth \\
\hline 1 & \multirow{10}{*}{$0.5 \mathrm{~mm}$} & $25.63(1.87)$ & $22.49(1.27)$ & $16.19(7.56)$ & $63.65(39.89)$ & 23.76 \\
\hline 2 & & $26.74(2.72)$ & $26.69(2.67)$ & $20.08(3.94)$ & $106.09(82.07)$ & 24.02 \\
\hline 3 & & $31.39(0.28)$ & $30.25(0.86)$ & $23.17(7.95)$ & $89.87(58.76)$ & 31.11 \\
\hline 4 & & $16.73(4.30)$ & $15.95(5.08)$ & $11.78(9.25)$ & $48.66(27.63)$ & 24.03 \\
\hline 5 & & $26.55(1.53)$ & $26.76(1.74)$ & $20.50(4.52)$ & $83.34(58.32)$ & 25.02 \\
\hline 6 & & $24.94(2.66)$ & $25.48(2.12)$ & $19.76(7.85)$ & $78.65(51.05)$ & 27.60 \\
\hline 7 & & $27.30(0.96)$ & $27.13(1.13)$ & $21.04(7.22)$ & $76.22(47.96)$ & 28.26 \\
\hline 8 & & $33.26(0.60)$ & $31.53(1.13)$ & $23.94(8.72)$ & 95.05 (62.39) & 32.66 \\
\hline 9 & & $19.87(8.07)$ & $21.40(6.54)$ & $16.24(11.70)$ & $62.66(34.72)$ & 27.94 \\
\hline 10 & & $30.21(0.37)$ & $30.13(0.45)$ & $23.29(7.29)$ & $90.76(60.18)$ & 30.58 \\
\hline
\end{tabular}

${ }^{\mathrm{a}}$ : given value to extract $z$ slice from the $\mathrm{PCD}$ at $\mathrm{DBH}$.

Table 3

Tree DBH estimated using circular fitting algorithms in PK stand.

\begin{tabular}{|c|c|c|c|c|c|c|}
\hline \multirow{2}{*}{$\begin{array}{l}\text { Individual } \\
\text { tree }\end{array}$} & \multirow{2}{*}{ Tolerance $^{\mathrm{a}}$} & \multicolumn{5}{|c|}{ Estimated tree DBH (error between estimated DBH and ground truth) } \\
\hline & & $\mathrm{C}$ & MEC & $\mathrm{CH}$ & E & Ground truth \\
\hline 1 & \multirow{10}{*}{$0.5 \mathrm{~mm}$} & $25.32(0.63)$ & $26.27(1.58)$ & $24.98(0.29)$ & $78.81(54.12)$ & 24.69 \\
\hline 2 & & $26.37(2.14)$ & $30.77(2.26)$ & $27.63(0.89)$ & $82.85(54.34)$ & 28.51 \\
\hline 3 & & $31.82(0.13)$ & $34.27(2.32)$ & $32.36(0.41)$ & $99.90(67.95)$ & 31.95 \\
\hline 4 & & $16.14(0.30)$ & $17.11(0.67)$ & $16.54(0.10)$ & $50.71(34.27)$ & 16.44 \\
\hline 5 & & $26.26(0.04)$ & 27.39 (1.09) & $26.64(0.34)$ & $82.51(56.21)$ & 26.3 \\
\hline 6 & & $24.57(0.74)$ & $26.53(1.22)$ & $25.12(0.19)$ & $77.15(51.84)$ & 25.31 \\
\hline 7 & & $26.68(0.70)$ & $28.52(2.54)$ & $27.34(1.37)$ & $83.82(57.84)$ & 25.98 \\
\hline 8 & & $27.35(2.20)$ & $29.86(0.31)$ & $28.55(1.00)$ & $85.91(56.36)$ & 29.55 \\
\hline 9 & & $17.33(0.98)$ & $19.78(1.47)$ & $18.18(0.13)$ & $54.44(36.13)$ & 18.31 \\
\hline 10 & & $29.92(0.85)$ & $31.29(0.52)$ & $30.42(0.35)$ & $94.01(63.24)$ & 30.77 \\
\hline
\end{tabular}

${ }^{\mathrm{a}}$ : given value to extract $z$ slice from the $\mathrm{PCD}$ at $\mathrm{DBH}$.

Table 4

Results of ANOVA test and RMSE and bias among the estimated DBH in PD and PK stands.

\begin{tabular}{|c|c|c|c|c|c|c|c|c|}
\hline \multirow{2}{*}{$\begin{array}{l}\text { Tree } \\
\text { species }\end{array}$} & \multicolumn{3}{|c|}{ ANOVA } & \multicolumn{5}{|c|}{ Tree diameter } \\
\hline & $\mathrm{df}$ & $F$ value & $p$-value & Algorithms & $\mathrm{DBH}(\mathrm{cm})$ & Standard error & RMSE & Bias \\
\hline \multirow{5}{*}{ PD } & \multirow{5}{*}{4} & \multirow{5}{*}{81.13} & \multirow{5}{*}{$<0.001$} & $\mathrm{C}$ & $26.26^{\mathrm{a}}$ & 1.50 & 3.25 & 0.94 \\
\hline & & & & MEC & $25.78^{\mathrm{a}}$ & 1.42 & 2.97 & 1.42 \\
\hline & & & & $\mathrm{CH}$ & $19.60^{\mathrm{a}}$ & 1.15 & 7.88 & 7.60 \\
\hline & & & & E & $79.50^{\mathrm{b}}$ & 5.19 & 54.38 & -52.30 \\
\hline & & & & Ground truth & $27.20^{\mathrm{a}}$ & 1.11 & - & - \\
\hline \multirow{5}{*}{ PK } & \multirow{5}{*}{4} & \multirow{5}{*}{82.1} & \multirow{5}{*}{$<0.001$} & $\mathrm{C}$ & $25.18^{\mathrm{a}}$ & 1.48 & 1.12 & 0.60 \\
\hline & & & & MEC & $27.18^{\mathrm{a}}$ & 1.57 & 1.58 & -1.40 \\
\hline & & & & $\mathrm{CH}$ & $25.77^{\mathrm{a}}$ & 1.49 & 0.65 & 0.01 \\
\hline & & & & E & $79.01^{\mathrm{b}}$ & 4.66 & 54.17 & -53.23 \\
\hline & & & & Ground truth & $25.78^{\mathrm{a}}$ & 1.51 & - & - \\
\hline
\end{tabular}

Different letters with DBH values represent significant differences among the four estimated tree DBHs and ground truth diameters at $p \leq 0.05$.

and $\mathrm{CH}(p<0.001)$. Among the circular fitting algorithms, MEC showed the lowest error and $\mathrm{C}$ showed the most significant RMSE among the circular fitting algorithms (Table 4). CH showed 
the lowest error in the PK stand in terms of both RMSE and bias value. However, E showed the largest RMSE and bias in the PK and PD sites (Table 4). The study revealed that C and MEC are the most suitable algorithms for estimating the diameter in the PD stand (Table 4). In addition, all algorithms except for E were suitable for estimating the diameter in the PK stand (Table 4).

\section{Discussion}

The use of smartphone images integrated with photogrammetric methods still has limitations in practical forest inventory assessment. Photogrammetry requires high computer power to process the large volume of image data. ${ }^{(5)}$ Also, noise and outlier removal from the PCD is still a challenge in achieving forest inventory assessment with high accuracy. However, the use of a smartphone, as owned by most people, still has considerable potential to efficiently investigate the forest structure. Advanced sensor technology and improved smartphone specs will allow the use of sensor technology in forestry sites with high efficiency. The forest industry in South Korea faces many challenges, including a lack of labor and its small scale. To overcome these challenges, the application of ICT technologies can be considered as an alternative for the rehabilitation of the Korean forest industry.

\section{Conclusions}

We investigated the possibility of applying smartphone-integrated computer vision in forest inventory assessment. Individual tree DBHs were estimated using four circular fitting algorithms: $\mathrm{C}, \mathrm{MEC}, \mathrm{CH}$, and least-squares ellipse. We found that the $\mathrm{CH}$ and $\mathrm{MEC}$ algorithms were most accurate for estimating tree DBH in a PD stand. In addition, all algorithms except for E were suitable for estimating tree DBH in the PK stand. However, advanced fitting algorithms are still required for practical forest inventory assessment. This study indicated the possibility of using a smartphone to investigate the forest structure efficiently.

\section{Acknowledgments}

This research was supported by a 2017 Research Grant from Kangwon National University (No. 520170347) and the Basic Science Research Program through the National Research Foundation of Korea (NRF) funded by the Ministry of Education (NRF-2021R1I1A1A01048775).

\section{References}

1 H. H. Shugart, S. Saatchi, and F. G. Hall: J. Geophys. Res. Biogeosci. 115 (2010). https://doi. org/10.1029/2009JG000993

2 M. Dassot, A. Colin, P. Santenoise, M. Fournier, and T. Constant: Comput. Electron. Agric. 89 (2012) 86. https://doi.org/10.1016/j.compag.2012.08.005

3 H. Pretzsch, K. Bielak, J. Block, A. Bruchwald, J. Dieler, H.-P. Ehrhart, U. Kohnle, J. Nagel, H. Spellmann, and M. Zasada: Eur. J. For. Res. 132 (2013) 263. https://doi.org/10.1007/s10342-012-0673-y

4 D. Panagiotidis, A. Abdollahnejad, and M. Slavík: Sensors 21 (2021) 301. https://doi.org/10.3390/s21010301

5 M. I. Marzulli, P. Raumonen, R. Greco, M. Persia, and P. Tartarino: Forestry 93 (2019) 411. https://doi. org/10.1093/forestry/cpz067 
6 T. E. Avery and H. E. Burkhart: For. Meas. (Waveland Press, 2015) 5th ed., Chap. 3.

7 S. A. Omule: For. Chron. 56 (1980) 222. https://doi.org/10.5558/tfc56222-5

8 Y. Fan, Z. Feng, A. Mannan, T. U. Khan, C. Shen, and S. Saeed: Remote Sens. 10 (2018) 1845. https://doi. org/10.3390/rs10111845

9 K. G. MacDicken: For. Ecol. Manage. 352 (2015) 3. https://doi.org/10.1016/j.foreco.2015.02.006

10 V. Kankare, X. Liang, M. Vastaranta, X. Yu, M. Holopainen, and J. Hyyppä: ISPRS J. Photogramm. Remote Sens. 108 (2015) 161. https://doi.org/10.1016/j.isprsjprs.2015.07.007

11 X. Liang, V. Kankare, J. Hyyppä, Y. Wang, A. Kukko, H. Haggrén, X. Yu, H. Kaartinen, A. Jaakkola, and F. Guan: ISPRS J. Photogramm. Remote Sens. 115 (2016) 63. https://doi.org/10.1016/j.isprsjprs.2016.01.006

12 L. M. Moskal and G. Zheng: Remote Sens. 4 (2012) 1. https://doi.org/10.3390/rs4010001

13 F. Giannetti, N. Puletti, V. Quatrini, D. Travaglini, F. Bottalico, P. Corona, and G. Chirici: Eur. J. Remote Sens. 51 (2018) 795. https://doi.org/10.1080/22797254.2018.1482733

14 M. Dassot, T. Constant, and M. Fournier: Ann. For. Sci. 68 (2011) 959. http://dx.doi.org/10.1007/s13595-011$\underline{0102-2}$

15 B. Brede, A. Lau, H. M. Bartholomeus, and L. Kooistra: Sensors 17 (2017) 2371. https://doi.org/10.3390/ s17102371

16 H. Huang, Z. Li, P. Gong, X. Cheng, N. Clinton, C. Cao, W. Ni, and L. Wang: Photogramm. Eng. Remote Sens. 77 (2011) 219. https://doi.org/10.14358/pers.77.3.219

17 J. Wu, W. Yao, S. Choi, T. Park, and R. B. Myneni: IEEE Geosci. Remote Sens. Lett. 12 (2015) 2267. https://doi. org/10.1109/lgrs.2015.2466464

18 W. Yao, P. Krzystek, and M. Heurich: Remote Sens. Environ. 123 (2012) 368. https://doi.org/10.1016/j. rse.2012.03.027

19 J. A. v. Aardt, R. H. Wynne, and R. G. Oderwald: For. Sci. 52 (2006) 636. https://doi.org/10.1093/ forestscience/52.6.636

20 Z. J. Bortolot and R. H. Wynne: ISPRS J. Photogramm. Remote Sens. 59 (2005) 342. https://doi.org/10.1016/j. isprsjprs.2005.07.001

21 P. Hyde, R. Nelson, D. Kimes, and E. Levine: Remote Sens. Environ. 106 (2007) 28. https://doi.org/10.1016/j. rse.2006.07.017

22 M. Lefsky, D. Turner, M. Guzy, and W. Cohen: Remote Sens. Environ. 95 (2005) 549. https://doi.org/10.1016/j. rse.2004.12.022

23 S. C. Popescu: Biomass Bioenergy 31 (2007) 646. https://doi.org/10.1016/j.biombioe.2007.06.022

24 S. Krisanski, M. S. Taskhiri, S. Gonzalez Aracil, D. Herries, and P. Turner: Remote Sens. 13 (2021) 1413. https://doi.org/10.3390/rs13081413

25 X. Liang, V. Kankare, J. Hyyppä, Y. Wang, A. Kukko, H. Haggrén, X. Yu, H. Kaartinen, A. Jaakkola, F. Guan, M. Holopainen, and M. Vastaranta: ISPRS J. Photogramm. Remote Sens. 115 (2016) 63. https://doi.org/https:// doi.org/10.1016/j.isprsjprs.2016.01.006

26 T. Mikita, P. Janata, and P. Surový: Forests 7 (2016) 165. https://doi.org/10.3390/f7080165

27 T. Schenk: Introduction to Photogrammetry, The Ohio State University, Columbus 106 (2005) 1st ed.

28 J. Morgenroth and C. Gómez: Urban For. Urban Greening 13 (2014) 198. https://doi.org/10.1016/j. ufug.2013.10.005

29 J. Miller, J. Morgenroth, and C. Gomez: Urban For. Urban Greening 14 (2015) 932. https://doi.org/10.1016/j. ufug.2015.09.001

30 M. Forsman, N. Börlin, and J. Holmgren: Forests 7 (2016) 61. https://doi.org/10.3390/f7030061

31 D. Panagiotidis, P. Surový, and K. Kuželka: J. For. Sci. 62 (2016) 357. https://doi.org/10.17221/92/2015-jfs

32 P. Surový, A. Yoshimoto, and D. Panagiotidis: Remote Sens. 8 (2016) 123. https://doi.org/10.3390/rs8020123

33 D. A. Kwak, W. K. Lee, and M. H. Son: J. Korean Soc. For. Sci. 94 (2005) 431. https://doi.org/10.7319/ kogsis.2013.21.2.027

34 D.-A. Kwak, W.-K. Lee, H.-K. Cho, S.-H. Lee, Y. Son, M. Kafatos, and S.-R. Kim: J. Plant Res. 123 (2010) 421. https://doi.org/10.1007/s10265-010-0310-0 


\section{About the Authors}

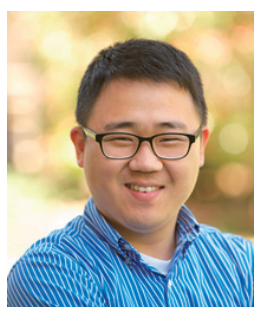

Heesung Woo received his B.S. degree from Kangwon National University, South Korea, in 2011, his first and second M.S. degrees from Kangwon National University, South Korea, in 2013 and Humboldt State University, CA, USA, in 2015, respectively, and his Ph.D. degree from the University of Tasmania, Australia, in 2020. From 2019 to 2020, he was a research professor at Kyungpook National University, South Korea. Since 2021, he has been a research professor at Kangwon National University. His research interests are in precision forestry, robotics in forestry, and data analysis in forest management. (whs1608@gmail.com)

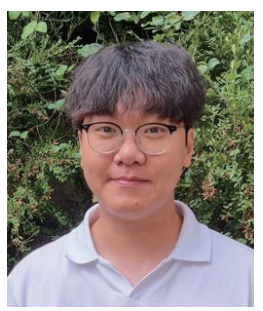

Ikhyun Kim received his B.S. and M.S. degrees from Kangwon National University, South Korea, in 2019 and 2021, respectively. Currently, he is a Ph.D. candidate at Kangwon National University, South Korea. His research interests include forest environment protection and eco-hydrology.

(kih9281@kangwon.ac.kr)

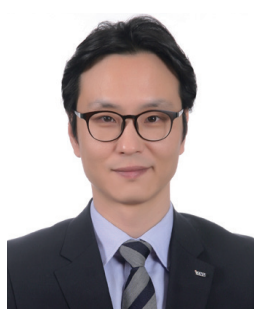

Byoungkoo Choi received his B.S. and M.S. degrees from Kangwon National University, South Korea, in 2002 and 2004, respectively, and his Ph.D. degree from Mississippi State University, USA, in 2011. From 2014 to 2015, he was a research scientist at the National Institute of Ecology, South Korea. Since 2015, he has been an associate professor at Kangwon National University. His research interests include eco-hydrology, watershed management, and forestry BMPs. (bkchoi@kangwon.ac.kr) 